\title{
ESTRUCTURACIÓN ORGANIZACIONAL: UN ENFOQUE SISTÉMICO
}

\author{
Organizational Structuring: A Systems Approach
}

Clemencia Morales Montejo PhD. ${ }^{1}$

\section{RESUMEN}

El cómo estructurar las organizaciones es un tema que siempre ha sido relevante. Por estructura se entiende la disposición y el orden de las partes dentro del todo, considerando el entorno complejo.

El enfoque sistémico es una interpretación que estima los diferentes puntos de vista de todos los actores de la organización, las partes interesadas y la interrelación entre estas. El utilizar metodologías de naturaleza holística permite que exista coherencia con la estrategia, los procesos, los actores y la información. Su complementariedad permite, a través de un proceso interactivo, llegar a una mejor estructuración organizacional.

Para su desarrollo, en primer lugar, se identifican y se definen metodologías sistémicas para la estructuración; en segundo lugar, el enfoque sistémico sugerido para desarrollar cada metodología sistémica; en tercer lugar, la forma de medir la estructuración en cada enfoque y las medidas de actuación para reconocer su efectividad; por último, el impacto en la estructura al utilizar las metodologías de forma complementaria, en un proceso interactivo.

El aprendizaje organizacional se facilita al utilizar este proceso ya que el conocimiento emerge de la interacción entre la organización, las metodologías y sus usuarios. Se trata de una relación investigaciónacción que incluye el entorno. El diseño, diagnóstico y rediseño organizacional surge de un proceso que se repite a través de comparaciones de mejora de la estructura organizacional. De esta forma, se alinean las metodologías hasta generar una Meta metodología.

Palabras clave: Estructura Organizacional, Modelos de Arquitectura Empresarial, Análisis Organizacional, Gobierno Corporativo, Medición del Desempeño y Efectividad.

\begin{abstract}
How to structure organizations is an issue that has always been relevant. In today's complex world, new ways of refining organizations are required so that they can respond quickly to the demands of the environment. The systems approach allows one to visualize an organization from a holistic perspective under different scenarios.

The complementarity of methodologies is an interactive process that allows one to achieve the best organization. The operation of an organization requires the participation of all organizational actors. By coordinating important factors such as strategies, objectives, processes, values, and organizational information, it is possible to build an interactive structure.

The first order of business will entail the defining of key terms associated with structuring methodology. Secondly, we will examine what types of views and perspectives are being adopted by organizations. Thirdly, we will turn our attention to the systemic approach and the importance of evaluating methodology. Fourthly, we will determine the best model to be used in each approach to a given situation. Lastly, we will observe the chosen methodology in action.

Organizational learning is defined as the process by which knowledge emerges from the interaction between the organization, methodologies, and its users in a research-action relationship, with respect to the environment. The design, diagnosis, and organizational redesign arises from a process that is repeated and improved upon through comparisons. It is through this process by which Meta methodologies are generated and aligned.
\end{abstract}

Keywords: Interactive Structuring, Business Architecture, Organizational Analysis, Corporate Governance, Measurement of Performance and Effectiveness.

1 www.clemenciamorales.com 


\section{DIFFERENT OBSERVATIONS OF ORGANIZATIONS}

Systems methodologies and models are related to organizational visions, and help to observe and determine the organizational structure. In Morales [1], some systemic models that were used in the practice of organizational evaluation were investigated. Some of these models have been applied in the practical work of organizational structuring. These models make it easier to adopt a flexible holistic perspective on organizational observation, allowing to develop hypotheses about its use and its complementarity.

This leads us to use the previously defined terms, in the steps shown below:

- Identify the most appropriate System Methodology to structure each type of organization by studying various methodologies and systems models.

- Identify the Systems Approach to use by extending the methodologies in a way that allows one to structure an organization properly. Also, it is necessary to determine how to integrate the different models and methodologies for the purpose of structuring the operational functions of the company effectively. A methodology may or may not include models.

- Identify how to measure the impact of the structuring by studying when the different types of methodologies are significant. The type of organization will influence under what conditions each model and methodology can be adopted.

- Identify how to recognize the effectiveness of complementing structuring methodologies. This will allow one to understand the criteria of structuring and constant feedback of an organization.

perspectives for structuring organizations
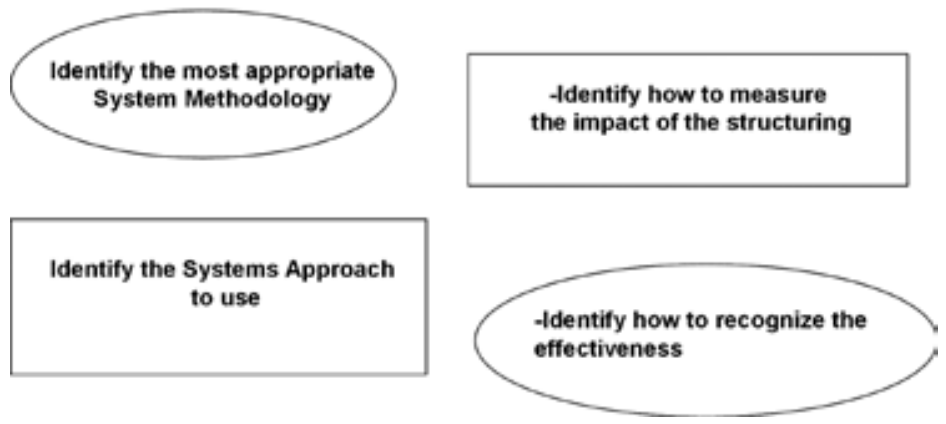

Figure1. Perspectives for structuring organizations. Prepared by the author.

\section{STRUCTURE THE ORGANIZATION HOLISTICALLY}

Studying an organization under particular metaphors is necessary to arrive at a better analysis. It is possible to have different organizational visions taking into account different organizational metaphors. These metaphors allow us to consider organizations from many perspectives: organizations as a machine, organizations as an organism, organizations as a brain, organizations as a political system, organizations with a specific culture, and organizations as an interconnected system of information and communication networks. Whatever approach is applied, it is necessary to define assumptions about the nature of the organization according to the structuring methodology used. 


\section{Ways of perceiving organizations under different perspectives}

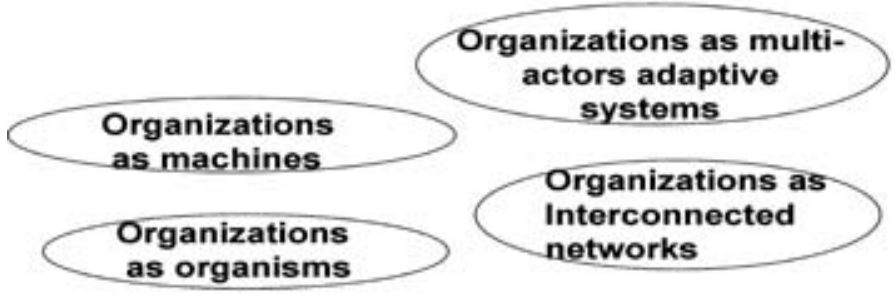

Figure 2. Ways of perceiving organizations under different perspectives. Prepared by the author.

To complete the analysis of the structure, it has to take into account the metaphor, the theory, and the method. These considerations make up the main argument.

Organizations today are built in a linear world with hierarchical structures, centralized, and closed from top to bottom, always belonging to the same owner with employees, resources, assets and scarce platforms. These organizations belong to the environment from the last century, when they enjoyed economies of scale, predictability and relative stability. However, the world has changed exponentially as a result of the development of new technology and globalization. The world becomes increasingly open and transparent, moving between scarce and abundant resources. Systems and platforms are needed for organizations to adapt and thrive in a resource-rich world. New organizational structures require models, organizational functions, technology platforms, and more open minds. We start talking about exponential organizations as the best, fastest and cheapest to react to the current environment. [2].

Studying how decisions are made, how management of change and organizational transformation is achieved, is indicative of a good organizational structure. It is essential to analyze an organization as a system both in theory and in practice. Ways of thinking and acting are dependent on the dynamics of corporate situations. The actors must move at the same speed at which corporate problems are solved.

The systems approach is necessary for visualizing decision-making and the management of change in new organizations.

- The Goal-Based Structuring Methodology could be supported by the Methodology of Interactive Management based on Warfield systems [3]. The Interactive Management Methodology provides a process for deciding the objectives and producing a mission and organizational strategy. The organization is visualized as an interactive mechanistic system in a process that emphasizes the cooperative and integrating coexistence of the members to achieve their maximum contribution in the definition of the strategic plan in a minimum time.

- The Systems Resource Structural Methodology based upon the idea that it is important to analyze the organization as a coherent organic systems, it is supported by the Viable System Model, Beer [4], [5], [6]. VSM is a useful model to address the impact of process structuring. It implies identifying the set of functional processes of the organization and comparing them with the MSV to verify that the structures and processes guarantee the adaptability and the efficiency. The organization is visualized as an organic system, where that include autonomy, coordination, control, development and cohesion.

- The Multi-Actor based Structuring Methodology is supported by Checkland SSM Checkland's [7] model of soft systems, which allows exploring a problematic situation among actors. The SSM offers alternatives to generate debate about possible changes needed to improve. This is 
how the organization is viewed as a political system with a specific culture. The actors' perceptions can be compared to judge what the organization is currently offering and thus structure it from a variety of different perspectives.

- In a Structuring Methodology based on a culture of interconnectivity, stakeholders can identify an organizational vision and generate commitment and consensus, in order to satisfy specific wishes of the actors involved. TOGAF [8] defines an "organization" as a collection of interconnected systems, under a specific vision, with a common set of objectives, processes, values and information. The term "organization" in the context of "organizational architecture" includes the information systems and the specific domains of these within the organization.

\section{THE IMPACT OF USING THE VARIOUS APPROACHES}

Methods of measuring organizational performance differ from each structuring approach, and may be qualitative or quantitative. It is necessary to select different ways of measuring the impact on organizational structuring by identifying the variables and indicators involved. Qualitative measurement depends on quality and is based on the subjective expression of situations that are considered personal opinions. Quantitative measurement is measured in terms of quantity and is capable of being expressed numerically, according to Scriven [9]. This requires making an important distinction between indicators of efficiency and effectiveness in each structuring approach.

Efficiency is used to analyze performance within the organization and depends on how well human, financial, technological, and informational resources are being used. It gives analysis criteria about the quality of different internal processes. Efficiency indicates whether or not something is being done correctly and at lowest cost.

Efficacy is a measure used to analyze the behavior of an organization in relation to its environment. It also shows whether or not the organization is doing what it is expected with its resources in its environment. In other words, are the expected results being achieved with the desired accuracy in the most suitable time? Efficacy is related directly to both corporate integration and operational coordination.

Effectiveness depends on the relationship between the objectives and the opportunities resulting from strategy management. This criterion of effectiveness embraces efficiency and efficacy criteria to measure corporate productivity. A successful evolution of the organization depends, simultaneously, on efficiency and efficacy. First of all, the level of efficiency and optimum efficacy prevailing in the enterprise must be systematically identified to achieve full effectiveness. [10].

The definitions of efficiency, efficacy, and effectiveness are likely to be employed differently in ach structuring approach. The definitions of effectiveness proposed by Gregory [11] do not relate specifically to one measurement but to the approaches as a whole. For example:

- In Goal-based structuring, numerical indicators are usually employed in assessing the extent of goals achievement. The Goal-Based Structuring Methodology must provide the necessary modeling and quantitative techniques that will allow the system's effectiveness to be measured in terms of its stated goals.

- The System-Resource-based structuring, may be quantitative in orientation because the structuring can be based upon organization performance. It can express cause and effect relationships between inputs, transformation and the results of each process, as stated by Morales [12, p. 166].

- The Multi-Actors-based structuring defines effectiveness as the ability of an organization to generate and perpetuate a culture which enables the individuals serving it to reach their full 
potential. Such an approach enhances an organization by improving its ability to change and adapt [11].

- The Structuring Methodology is based on a culture of interconnectivity. Technologies are united in open platforms and ecosystems that amplify organizational innovations. They help organizations and people connect with each other, thereby giving them the power to combine technologies and information to create new products and services. This ability to combine and recombine technologies with people and take advantage of innovations produces an organizational impact that can be measured.

The definition of an integrated set of indicators provides the basis for a more successful organizational structuring process. The combined use of these methodologies should be at the center of the integral process that allows for the simultaneous measuring of objectives, the potential for survival, the satisfaction of the stakeholders, and connectivity. The complementarity of the structuring methodologies can be useful in the measurement of the impact and helps to visualize the internal and external problems in the organizational articulation.

\section{THE COMPLEMENTARITY OF DIFFERENT OBSERVATIONS}

Each organization is quite unique at any given moment in time; it has its own goals, processes, politics, culture, and information. These variables, and the influence of a complex and ever-changing world, make sustainable organizations extremely diverse in character. The structure must consider these elements in an integrated way.

Figure 3 displays a chart of the various organizational structuring methodologies along with their associated views and system models.

\begin{tabular}{l||l|l}
$\begin{array}{l}\text { Structure } \\
\text { Methodology }\end{array}$ & $\begin{array}{l}\text { View of the } \\
\text { Organization } \\
\text { As a: }\end{array}$ & $\begin{array}{l}\text { Suggested } \\
\text { Systems } \\
\text { Approach }\end{array}$ \\
\hline \hline Goal-Based & Machine & $\begin{array}{l}\text { Interactive } \\
\text { Management }\end{array}$ \\
\hline $\begin{array}{l}\text { Systems- } \\
\text { Resource }\end{array}$ & $\begin{array}{l}\text { Adaptive } \\
\text { System }\end{array}$ & $\begin{array}{l}\text { Viable } \\
\text { System Model }\end{array}$ \\
\hline Multi-actor & $\begin{array}{l}\text { Pluralistic } \\
\text { System }\end{array}$ & $\begin{array}{l}\text { Soft } \\
\text { Systems } \\
\text { Methodologies }\end{array}$ \\
\hline Connectivity & $\begin{array}{l}\text { Inter-conected } \\
\text { System }\end{array}$ & $\begin{array}{l}\text { Organizational } \\
\text { Architecture }\end{array}$ \\
& &
\end{tabular}

Figure 3. Organizational structuring methodologies. Prepared by the author. 
It is possible, however, that an organization needs more than one methodology. Therefore, complementarity is important for monitoring both internal and external changes in different situations and moments. Structuring would not be successful if organizational performance over time was not measured by different methods.

Everything discussed to this point helps to inform and expand the strategy and vision of an organization. One must understand technology and its transformative effect on information because data facilitates the efficient management of an organization. Application management helps to define the requirements for a logical and physical structure.

\section{CONCLUSION}

Structuring methodologies are based on goals, system resources, multi-actors, and connectivity. When implementing structuring methodologies, it is crucial to consider the varying needs and conditions of each organization in order to achieve a structure that is more in line with the organization.

Methodologies and complementarity will be discussed in greater detail in future articles. In addition, practical discussions on the application of specific methodologies in case studies will be presented. The organizations sampled in the case studies can be classified as either commercial, industrial, governmental, or social entities.

\section{RELEVANT TERMS TO REMEMBER}

The terms defined in this paper include: structure, methodology, approach, paradigm, metaphor, model, and vision. An understanding of the term structure is essential for any discussion on organizational structuring. Some terms are explained with simple definitions from Wikipedia and later in the context of organizational structuring. These definitions interrelate with each other for their use in the development of a Meta-Methodology.

\section{Structure}

Structure is the arrangement and order of the parts within a whole. It can also be understood as a system of bounded coherent concepts, whose purpose is to specify the essence of the object of study. The structural elements are permanent and basic, are not subject to circumstantial or conjectural considerations, but are the essence and raison d'être of the same system. [13].

Choosing a particular structure depends on the characteristics of the stakeholder involved and their requirements. Determining an appropriate structure is dependent upon current performance and strategies of the organization as a whole.

With regards to organizational structure, it is important to understand a wide array of concepts. These concepts include, but are not limited to, organizational differentiation, how tasks are divided, where controls are exercised, where decisions are made, and where tasks are integrated, coordinated and planned. According to the model of Katz and Kahn, "the structure of the organization represents the formalization of relations between the technical and psycho-social subsystems. The structure is much more fragile and provisional than any material structure of an organism" [14]. 


\section{Methodology}

Methodology can often be defined as the study or choice of a method pertinent or appropriately applicable to a given object [15].

In the context of organizational structuring, the choice of methodology is dependent on organizational views and is oriented towards learning and decision-making processes. In this way, methodology is a vehicle for developing a deeper knowledge of an organization.

It is necessary to reach an interactive process by taking the following into account: content, language, and information. It is also essential to use consensus methods to promote interactive structuring processes and create the best conditions to support the process. The actors are the users of the methodologies. All of these elements are interrelated in an interactive process.

It is vital to develop an ability to understand interactive methodologies. Although there is an organizational capacity to implement medium and long-term methodologies, it is risky to use them in an interactive way due to the minimum amount of time between their establishment and their execution. Users should be able to process information and learn very quickly. Since structuring methodologies are in constant state of evolution, interactivity is developed in a flexible methodology that will lead to the creation of Meta-Methodologies.

The way to develop, enrich, and learn from interactive structuring depends on the orientation of users in a learning process.

\section{Approach}

An approach is a pre-existing knowledge with an interpretation of problematic situations, a set of objectives, a collection of methods, and an archetype that marks a conduction [16].

The systems approach takes into account the different points of view of all organizational actors, the stakeholders, and the interrelationship between them. This pluralistic approach is based on a concern for the political and cultural aspects of the organization. Satisfied actors are primarily responsible for the success of the organization.

\section{How to complement approaches with methodologies}

The use of isolated methodologies is insufficient for achieving a systemic organizational structure. The systems approach is necessary for visualizing the organizational structure under different organizational situations and assessing performance.

The articulation of different approaches, as well as their implications, is vital for observing the effectiveness of changes within the organization. The combination of approaches is carried out at different levels of recursion, which allows for more informed structuring. It is also important to analyze how these approaches can be used in a complementary way to measure effectiveness through the identification and measurement of indicators.

As with any readjustment to an organization, adopting these approaches implies changes in an institution's philosophy and culture. Changes will be felt in leadership, planning, information, communication, and the sharing of knowledge within the organization. This philosophy and its principles will guide organizational structuring.

The organization is analyzed interactively as a cybernetic system that processes information through closed feedback circuits, allowing short and long term organizational balancing.

\section{Paradigm}

The word paradigm is used to indicate a pattern, a model, or an archetype. From a cybernetics perspective, it means a conceptual preprogram for the ordering of even more chaotic data in relative terms [17]. 
"A new organizational paradigm tells us about a new flexible, connective, evolutionary, innovative, meaningful and networked organization. From it we have to abandon the old metaphors and begin to think of a set of flows and elements that are self-produced and reconfigured. Think of a network of publics on which we depend and in a network of conversations from which the innovation is born" [18].

\section{Metaphor}

A metaphor consists of a type of analogy or association between elements that share some similarity of meaning by replacing one for the other in the same structure. A metaphor exposes two things altogether that allow the suggestion to be compared and interpreted as a single concept [19].

A metaphor is a mental comparison of reality, and implies a way of thinking and seeing. Metaphors are used when it comes to understanding one element of experience in terms of another. Each metaphor allows one to visualize the organization from a different perspective. It also makes it possible to evaluate the success of the organization through the presence or absence of certain variables in different contexts.

\section{Model}

A model is an abstract, conceptual, graphic, or visual representation of systems or processes in order to analyze, describe, explain, simulate (in general: explore, control and predict) those phenomena or processes. It can be said that a model is a simplified representation form of reality [20].

Methodologies are cyclical with their beginnings and endings. Conversely, models can be eternal as they transform and adapt to the environment. When it comes to the development of organizational structuring, a model is an abstraction of reality that requires continuous thinking as to what the organizational structure can eventually be. Thinking about the structural model of an organization is practical only if there exists the ability to build it. These models will have to be constructed, validated, and developed from their subsystems.

"Selecting the most appropriate way to represent the model is a crucial point in defining the model and can start as simple as that, and grow in value as the model is understood and deepened further" [21, p.172].

Applied to Business, Ponti [22] defines: "A Business Model is a conceptual organizational representation, which tries to explain how the organization is able to create, distribute and extract value from its operations. The functions of a business model are:

Articulate the value proposition: What value is created? What solution does it bring?

Identify the market segment(s) where the product would be sold.

Define the structure of the value chain required to create and distribute the solution being offered.

Specify the generation of value.

Describe the position of the product within the value chain.

Formulate the competitive strategy by which the firm that innovates will have a sustainable advantage over the competition. Make sure your business model determines value creation and captures part of that value."

\section{Vision}

Vision is the ability to see beyond time and space. By doing so, one is able to build a desirable future state in their mind and bring clarity to what you want to do and where you want to take an organization [23]. 
Organizations are the output of many new ideas, visions, models, norms, and beliefs which converge in a flexible, fragile, and provisional structure. This must allow the knowledge and time of processes to be accelerated in a structured way so as to obtain maximum use of human talent.

The various approaches to structuring an organization are directly related to its established vision. The key question is: What organizational vision can be adopted to promote a better organizational structure?

\section{Organizational Structuring considering methodology, vision, approach and model}

Here we summarize the different visions of the organization, the different methodologies to structure the organizations and the systems approach suggested to carry out the structuring. In this way, there is a relationship between vision, methodology and approach.

Successful organizations recognize that shared values increase commitment and productivity. Through shared visions, values, and goals, a broader and more reliable view of the organization is produced. This allows the organization as a whole to work in the same direction according to its values. An effective performance is an efficient way of building agreement, guiding decision-making, and aligning the actions of organizational members. In this way, organizational learning is embedded in a Meta-Structuring methodology. This methodology arises as a consequence of the different visions, reflections, and interpretations of the different organizational situations.

\section{REFERENCES}

[1] C. Morales, "A systems study of the scope and significance of evaluation methodologies in the management of organizations in Colombia”. PhD Thesis, Lincoln School of Management, 2000.

[2] I. Salim et al, Exponential organizations. USA: Singularity University Book, 2014.

[3] J. Warfield, Societal Systems Planning, Policy And Complexity. Salinas, California, USA: The Systems Inquiry Series, Intersystems Publications, 1989.

[4] S. Beer, The Heart Of The Enterprise. Chichester, England: Wiley, 1979.

[5] S. Beer, Diagnosing The System For Organizations. Chichester, England: Wiley, 1987.

[6] S. Beer, Beyond Dispute: The Invention Of Team Syntegrity. Chichester, England: Wiley, 1994.

[7] P. Checkland and J. Scholes, Soft Systems Methodology In Action, Chichester, England: Wiley, 1990.

[8] Togaf, (2012) The Open Group Architecture Framework (TOGAF). John Spencer, Director Architecture Forum, Version 8 - "Enterprise Edition, Burlingame, 5th February 2012. http://www.opengroup.org/architecture/togaf8/index8.htm

[9] M. Scriven, Evaluation Thesaurus. 4th ed. London: Sage Publications, 1991.

[10] C. Morales, "Stability Indicators, A Tool For Organizational Planning And Control”. Master Of Philosophy Thesis, The University Of Aston In Birmingham, 1992.

[11] A. Gregory, "Organisational Evaluation: A Complementarist Approach". PhD Thesis, University Of Hull, 1994.

[12] C. Morales, Evalúe la gestión de su empresa: más allá de la estrategia y de los indicadores, Bogotá, Colombia: Panamericana Editorial, 2005.

[13] "Estructura", Wikipedia, 2019. [Online]. Available: https://es.wikipedia.org/wiki/Estructura. [Accessed: 30-ene-2019]

[14] D. Katz and R. L. Kahn, The Social Psychology of Organizations. 2nd ed. Chichester, England: Wiley, 1978. 
[15] "Metodologia", Wikipedia, 2019. [Online]. Available: https://es.wikipedia.org/wiki/ Metodolog\%C3\%ADa. [Accessed: 30-ene-2019]

[16] "Enfoque", Wikipedia, 2019. [Online]. Available: https://es.wikipedia.org/wiki/Enfoque\#cite_ note-BunArd-1. [Accessed: 30-ene-2019]

[17] "Paradigma”, Wikipedia, 2019. [Online]. Available: https://es.wikipedia.org/wiki/Paradigma. [Accessed: 30-ene-2019]

[18] R. A. Pérez, "Diseñar estrategias es diseñar significados, sentidos, resumen de Héctor Téllez Luna y María Isabel Cortes”. Revista ANDA, año 16, no. 46, pp. 22-25, 2012.

[19] "Metáfora”, Wikipedia, 2019. [Online]. Available: https://es.wikipedia.org/wiki/Met\%C3\%A1fora. [Accessed: 30-ene-2019]

[20] “Modelo", Wikipedia, 2019. [Online]. Available: https://es.wikipedia.org/wiki/Modelo. [Accessed: 30-ene-2019]

[21] C. Morales, El emprendedor de organizaciones innovadoras. Bogotá, Colombia: Siglo del Hombre Editores, 2014.

[22] F. Ponti, Los siete movimientos de la innovación. Bogotá, Colombia: Norma, 2009.

[23] "Definición de visión”, Definición.org, 2019. [Online]. Available: https://definicion.org/vision. [Accessed: 30-ene-2019]

[24] M. C. Jackson, Systems Methodology For The Management Sciences. London, England: Plenum Press, 1991. 